\title{
COVID 19 Related Social Distancing Effects on Carbon Monoxide Levels in a Populated
}

\section{Southeast Asia City}

Andrio Adwibowo

\author{
Environmental Health Dept., Public Health Fac., Univ. of Indonesia, Depok \\ West Java 16424, Indonesia \\ Email: adwibowoa@gmail.com
}

\begin{abstract}
The social distancing as a response to COVID 19 pandemic has led to the exceptional reductions of daily routine people activities and vehicle uses mainly in city. This same situation was also experienced by several busy, large, and populous cities in Southeast Asia (SA) countries. Correspondingly, this study aimed to test the hypothesis that the social distancing implementation period has increased the air quality in the term of carbon monoxide (CO) emission reduction as drawn from Jakarta city as an example of the one of populated cities in SA region. The $\mathrm{CO}$ was measured in parts per billions (ppb) and monitored on the daily basis employing remote sensor platform. The monitor periods were started from January, February, March, and April 2020 with 10 measurement days for each month. The social distancing was implemented from mid of March to the recent April. The CO measurement data were statistically tested to justify the significant effects of social distancing on the CO levels. Based on the CO data analysis, the order of CO mean by months is February > January > March > April. The CO levels for January, February, March, and April were 87.46 ppb (95\%CI: 83.54-91.37), 88.20 ppb (95\%CI: 81.65-94.74), 86.38 (95\%CI: 81.06-91.69), and 78.68 (95\%CI: 74.03-83.32) respectively. This study also find significant difference $(\mathrm{p}<0.05)$ of $\mathrm{CO}$ levels especially in April when social distancing has been implemented. Hence, these findings illustrate the potential air pollutant reduction gained from implementing social distancing as can be seen in April.
\end{abstract}

Keywords: city, CO, COVID 19, emission, social distancing.

\section{Introduction}

Recently, air pollution has been known as an underlying cause and determinants of a wide variety of disease processes linked with a range of pulmonary, cardiovascular, and immune system disorders. Air pollution is caused by a heterogeneous mixture of gases and particulate matter. Carbon monoxide (CO), nitrogen dioxide, sulfur dioxide, and ozone are known as the main gaseous components of air pollution. $\mathrm{CO}$ is a byproduct of the incomplete combustion of hydrocarbons. Common sources of CO include motor vehicle exhaust, heating unit, tobacco smoke, gas stove pollution, partial combustion of oils, coal, wood, 
kerosene, and other fuels generate $\mathrm{CO}$. Because of variety of $\mathrm{CO}$ sources in the environment, then this makes $\mathrm{CO}$ becomes a common contaminant of air pollution in both indoor and outdoor environments.

In parallel with anthropogenic activities lead to the volume of vehicle on the road and fuel combustion, the $\mathrm{CO}$ levels are high. Especially in the large city, the $\mathrm{CO}$ from motor vehicle emissions contributes to $70 \%$ of air pollution and have increased the COHb blood levels (Topacoglu et al. 2014, Levy 2015). In the city, the measured CO level range in the vehicle was 4.40-39.78 ppm (Odekanle et al. 2017). The CO levels in city are related with the vehicle volume and the traffic as well. Brice and Roesler (1966) reported that the traffic density denotes as number of vehicles per minute was positive correlated with the $\mathrm{CO}$ levels. The CO levels for vehicle number per minute equals to 0-39, 40-59, and 60-100 vehicles/minute were 16 ppm, 23 ppm, and 28 ppm respectively.

Jakarta is one of the large and populated cities in the Southeast Asia region. The city is occupied with 10.135.030 people followed by Bangkok (8.750.600 people) and Ho Chi Minh city (7.981.411 people). Hence this number has made Jakarta as the most populated city in comparison to other cities in Southeast Asia countries. The traffic in Jakarta road is dominated by motorcycle, 4 wheels/passenger vehicle, and bus. The volumes of those vehicles based on survey in 2018 were 14.745.590, 3.997.670, and 329.310 units. Those high volumes of vehicle may contribute to the CO levels. According to Darmanto and Sofyan (2012), it was estimated that the vehicle alone has released 2.970 .870 ton/year CO and this equal to $99.94 \%$ of $\mathrm{CO}$ emitted in that year. Likewise, monthly $\mathrm{CO}$ was equal to $2.28 \mathrm{mg} / \mathrm{m}^{3}$.

Recently, due to the COVID 19 pandemic, there is a social distancing regulation that urges people to stay at home and consequently limit the uses of vehicles. Jakarta city itself has started the social distancing since $16^{\text {th }}$ March 2020 until now. During the implementation of social distancing in Jakarta, it is observed that the volumes of vehicle are reduced. Likewise, it has been hypothesized that the COVID 19 related social distancing and movement restriction can lead to the reductions of vehicle volume and it will also reduce the air pollutant and increase the air quality. Hence, this study aims to measure how the social distancing can affect the CO levels in Jakarta.

\section{Methods}

\subsection{Study area and period}

The study area was located in the Jakarta city, Indonesia. For the study period, the study was conducted from January, February, March to April 2020. This period consisted of 4 month monitoring and aimed to cover the whole comprehensive conditions included pre and post social distancing periods. January, February, and mid of March 2020 were the period before the social distancing was implemented. The mid of March 2020 and end of April (current time) were considered as the condition when the social distancing has been implemented. 


\subsection{CO monitoring}

The CO monitoring was done in 10 random consecutive days per month. Saturday and Sunday were excluded from monitoring to avoid the data bias since there were no vehicle activities normally during holiday. Due to its accuracy and coverage of study area, this study employed remote sensor approach as platform to monitor and obtain the $\mathrm{CO}$ data. Furthermore, the $\mathrm{CO}$ was measured in parts per billion (ppb) and collected by gathering emission of energy at $700 \mathrm{~nm}$ to $1 \mathrm{~mm}$ wavelength at atmosphere column.

\subsection{Statistic and data analysis}

All the data were represented as spatial data to represent the city overlaid with the CO interpolation and bean plot graphic presentation. All the data will be calculated for their mean and $95 \%$ Confidence Interval (CI). The $\mathrm{t}$ test was used to determine if there is a significant difference between the means of $\mathrm{CO}$ monitoring between months representing the pre and post social distancing periods.

\section{Results}

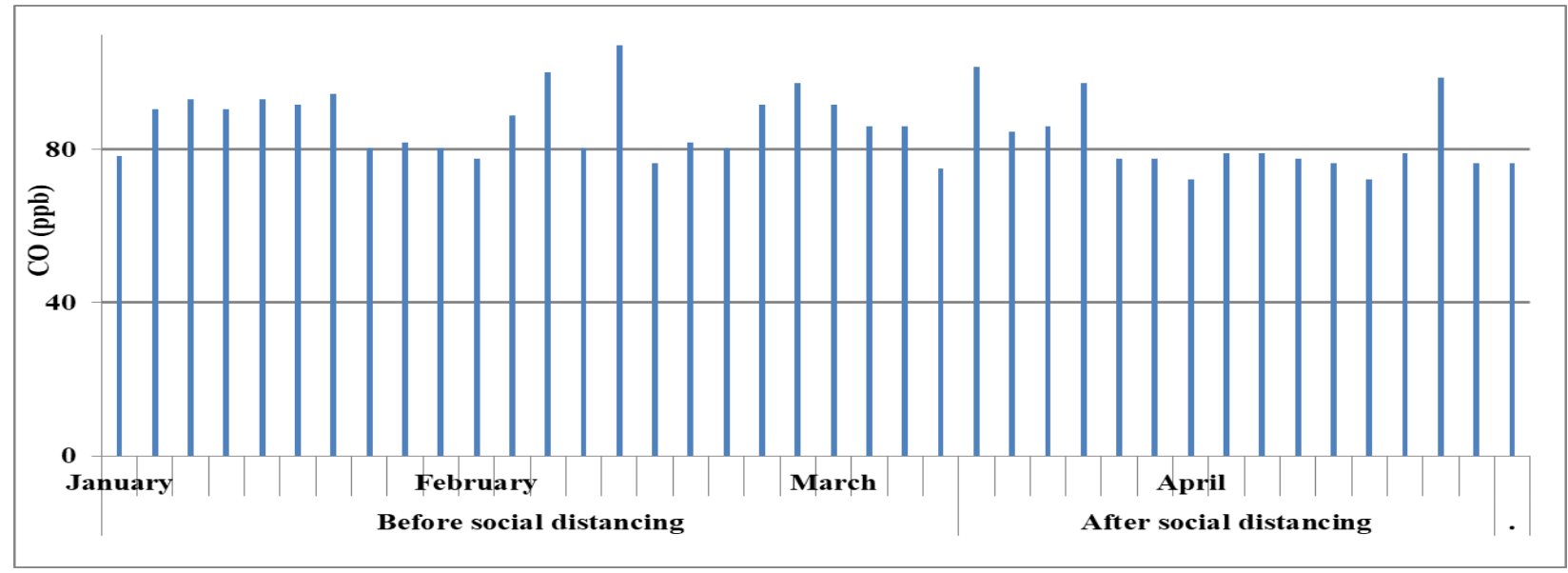

Figure 1. The chronological orders of CO (ppb) comparisons before social distancing (January, February, mid March 2020) and after social distancing (mid March, April 2020) in Jakarta city.

Table 1. The CO (ppb) comparisons for January, February, March, and April 2020 in Jakarta city

\begin{tabular}{cccccc}
\hline \multirow{2}{*}{ Month } & \multirow{2}{*}{ Mean $(\mathrm{n}=10)$} & $\mathrm{SD}$ & \multicolumn{2}{c}{$95 \% \mathrm{CI}$} & \multirow{2}{*}{ Sig. $(\mathrm{p}<0.05)$} \\
\cline { 4 - 5 } & & & Lower & Upper & \\
\hline January & 87.46 & 6.31 & 83.54 & 91.37 & $\mathrm{p}>0.05$ \\
February & 88.20 & 10.56 & 81.65 & 94.74 & $\mathrm{p}>0.05$ \\
March & 86.38 & 8.57 & 81.06 & 91.69 & $\mathrm{p}>0.05$ \\
April* & 78.68 & 7.49 & 74.03 & 83.32 & $\mathrm{p}<0.05$ \\
\hline
\end{tabular}

*Significant at $\mathrm{p}<0.05$ 


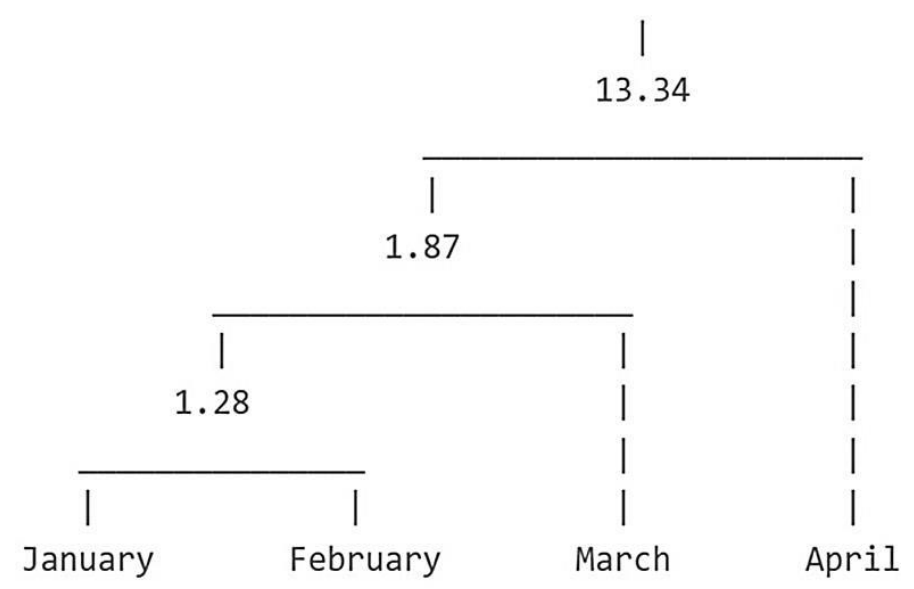

Figure 2. The cluster analysis with Euclidean distance score for CO (ppb) comparisons for January, February, March, and April 2020 in Jakarta city.

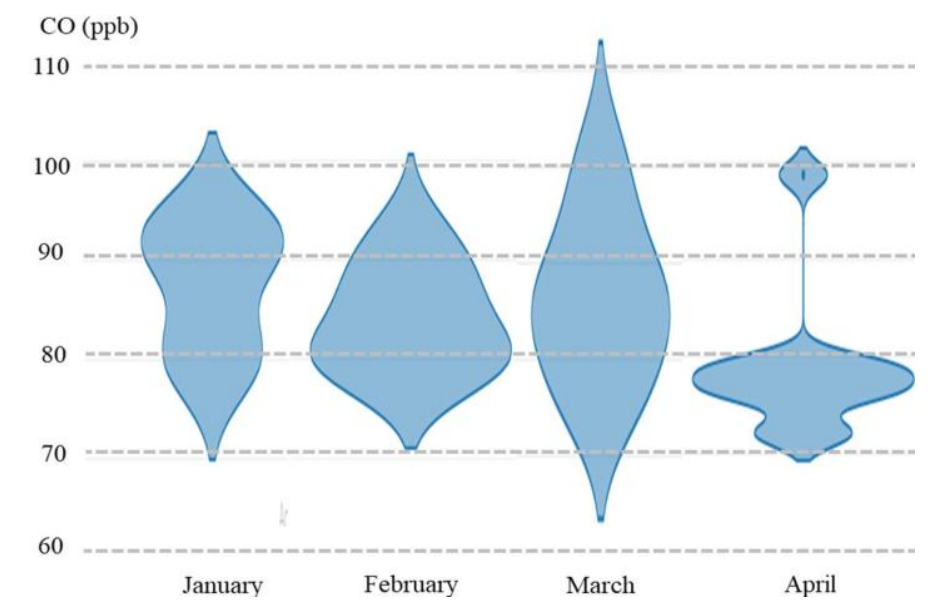

Figure 3. The bean plots for CO (ppb) comparisons for January, February, March, and April 2020 in Jakarta city.

Figure 1 shows a comprehensive chronological CO level by months in Jakarta city. The timely order graphic covers $40 \mathrm{CO}$ level monitoring days from the first of January to the end of April. The social distancing in Jakarta city was implemented in the mid of March until now. It is obvious that the CO has decreased in the April when the social distancing has been applied. In January, February, and March the CO levels were still above 80 ppb. Even though there were several days that the CO levels were below 80 ppb. However, in April most monitoring days have CO levels below $80 \mathrm{ppb}$ and only 1 day that $\mathrm{CO}$ fluctuated above $80 \mathrm{ppb}$.

More detail calculations (Tabel 1) show that the order of CO mean by months is February > January > March > April. The CO levels for January, February, March, and April were 87.46 ppb (95\%CI: 83.5491.37), 88.20 ppb (95\%CI: 81.65-94.74), 86.38 (95\%CI: 81.06-91.69), and 78.68 (95\%CI: 74.03-83.32) 
respectively. Based on the statistical analysis, the CO levels in April were significantly different $(\mathrm{p}<0.05)$, separated from the other months (Figure 2), and have lower CO compared to the other months (Figure 3). The CO in January, February, and March were tends to be similar ( $>>0.05$, Table 1$)$ and higher than CO in April (Figure 3).

The Figure 4 shows the spatial interpolations of daily $\mathrm{CO}$ overlaid with the Jakarta city map from January to April. Each month is represented with 10 monitoring days. It is obvious the degradation of CO classification colors from January to April. Months of January, February, and March were dominated with more dark colors indicated high CO levels. While in April, those dark color maps were replaced with more pale color maps. This indicates low CO levels observed in April.

\section{Discussions}

The data presented in here were comparable with findings of other $\mathrm{CO}$ level measurements from other large cities. The vehicle emission was also responsible for $\mathrm{CO}$ levels in cities as reported. For several decades, CO level measurements have been used as versatile tools to trace the $\mathrm{CO}$ emission within the atmosphere, mostly with the focus on vehicle emission (Holloway et al. 2000). Nowadays anthropogenic activities and life style contribute to the rapid urbanization and the increase of metropolitan areas worldwide with the populations exceeding more than a million people. This condition leads to the severe traffic and industrial activities in those regions and contribute to the high CO levels causing adverse effects on air pollution. According to Stephens et al. (2008), during the peak hour and when intense traffic occurred in Mexico city, the CO can reach to the levels equal to $9300 \mathrm{ppb}$. The same conditions where the traffic was the source of CO pollution were also been reported in the Kuwait city (Elkarim et al. 1991), Dhaka city, Bangladesh (Hasan et al. 2013), and Sao Paolo, Brasil (Rosante et al. 2017).

Study by Zhao et al. (2018) has provided detail analysis on how the vehicle and traffic volumes have an effect on the road based pollutants including $\mathrm{PM}_{2.5}, \mathrm{NO}_{\mathrm{x}}$, and CO. It was observed that $\mathrm{PM}_{2.5}$ and NOX level had a correlation with traffic volume with a correlation coefficient of 0.922 . While the correlation coefficients of traffic volume with CO concentrations was 0.853 .

The important point from this study is the CO levels are related to the traffic and vehicle reductions resulted from the social distancing and lockdown measure aims to reduce the spread of COVID 19. Since the lockdown limits or even forbids the use and movement of vehicle, then it was hypothesized that the social distancing and lockdown may affect the vehicle emission and air pollution as well. This hypothetical condition has been reported widely even though the body of scientific literature regarding this issue was very limited. The one study that has reported the effects of lockdown was a paper by Venter et al. (2020). In their study, they have reported that there were reduction of $\mathrm{NO}_{2}, \mathrm{O}_{3}$, and $\mathrm{PM}_{2.5}$ amid 2 week lockdown in China and India. The reported percentage reduction of $\mathrm{NO}_{2}, \mathrm{O}_{3}$, and $\mathrm{PM}_{2.5}$ were $-29 \%$ (95\% CI: $-44 \%$ to $-13 \%),-11 \%$ (95\% CI: $-20 \%$ to $-2 \%$ ), and $-9 \%$ (95\%CI: $-28 \%$ to $10 \%)$ respectively. 
However their study did not include the CO levels. In the Jakarta city as reported in this study, the CO levels were observed lower in April than CO levels measured in January, February, and March. In this city, the social distancing was implemented since the mid of March. The social distancing has caused the closures of activities like school, administration, and business. Likewise, this condition has also reduced the numbers of vehicles since the vehicle users have to stay at home. Several days after social distancing in March, the CO still has the level which is equal to the level before social distancing was implemented. However there was a steady declining trend observed after the implementation of social distancing. A single spike of $\mathrm{CO}$ level was observed during social distancing in the end of April even though the number of spike was less than number of spike observed in January and February before social distancing period.

The spatial interpolation to describe in detail the $\mathrm{CO}$ level spatial distribution was also comparable to other studies. In order to investigate the road based CO pollution, Khana and Arsalan (2017) have employed GIS and associated spatial statistics which has been recognized as a basic tool within the environmental health area that can be used to analyze and map the disease incidence data. The spatial interpolation was also a common method to estimate the $\mathrm{CO}$ levels in a certain area while the measurement in that area is limited. Furthermore, the spatial air pollutants mapping clearly can provide significant contribution to mark dispersion of air borne pollutants. (Adedeji et al. 2016).

The context of how the COVID 19 lockdown can be related to the air quality and airborne pollutant reduction are very interesting and growing matters. The COVID 19 itself is still spreading and growing in many countries in the world. Following that situations, those countries have implemented lockdown measures. Hence it is important to increase the numbers of study on association of lockdown and air quality improvement through the use of robust measurement tools and development of more determinants.

\section{Conclusions}

Based on our understanding, this is the first study in the Southeast Asia urban setting that investigates the relationships and how the COVID 19 pandemic related social distancing can affect the air pollution magnitude in this case the CO levels. The novelty of this study is the use of remote and spatial CO level measurements combined with the robust statistical method to readjust the variation of CO levels as the results of social distancing. In this study analysis, the study has accounted for CO level reduction during monitoring in the period when the social distancing has been applied in the Jakarta city.

\section{Recommendations}

Controlling the air pollution especially in populated cities in Southeast Asia countries is quite challenging. Determinants contribute to this challenge are related to the livelihoods that highly dependent on the use of vehicles. Nonetheless, the social distancing has informed and even provided us with a window of opportunity that there is an alternative way that can be used as a versatile tool in controlling 
the air pollution mainly the $\mathrm{CO}$ levels. As vehicle and its emissions are a known major determinant to city air pollution, it is possible to improve the air quality by reducing the vehicle and traffic volumes through social distancing approach and embedded this approach to the formal regulations.

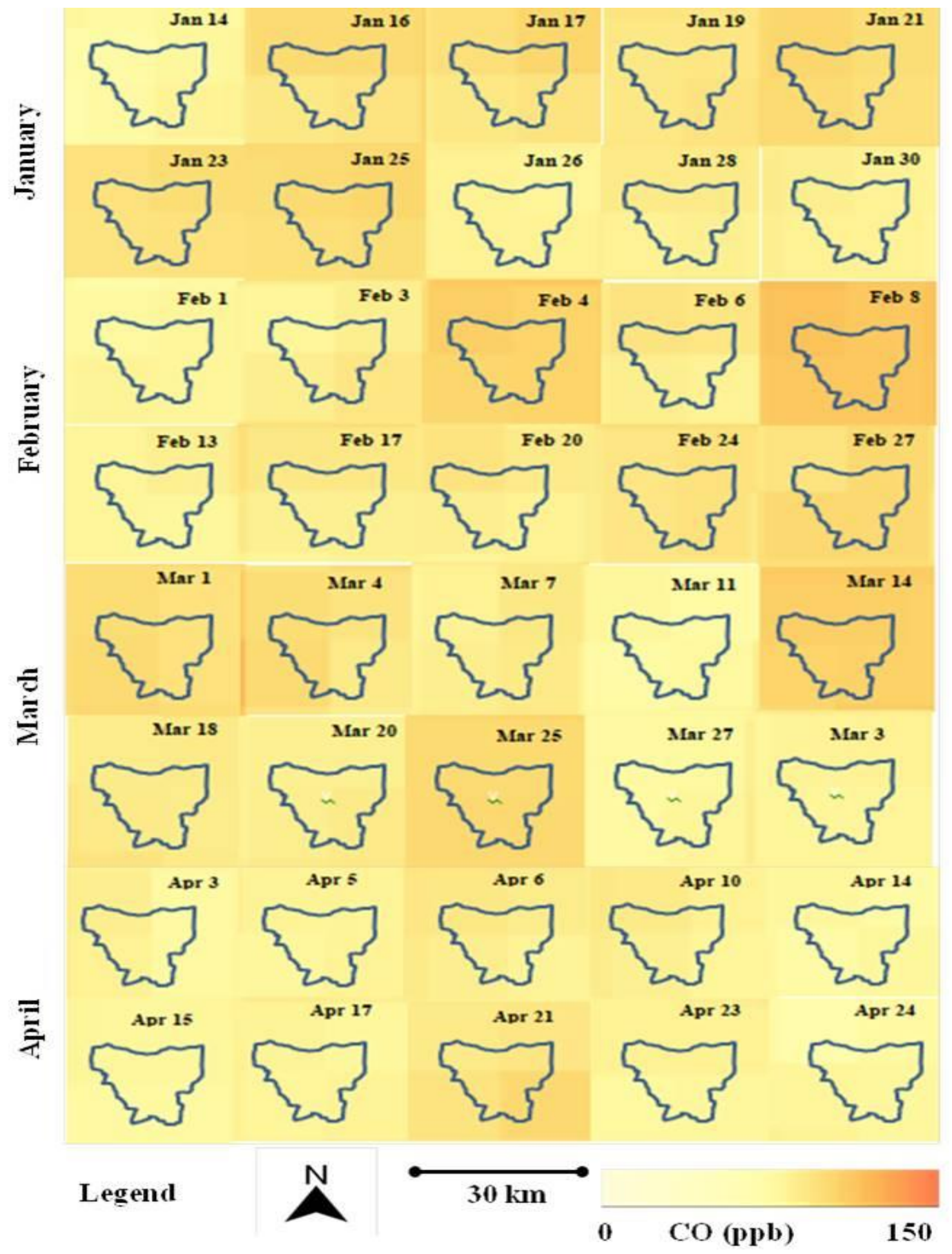

Figure 4. Spatial interpolation of daily CO (ppb) overlaid with the Jakarta city map from January to April 2020. 


\section{References}

Adedeji OH, Oluwafunmilayo O, Oluwaseun TAO. 2016. Mapping of Traffic-Related Air Pollution Using GIS Techniques in Ijebu-Ode, Nigeria. IJG 48 (1): 73 - 83.

Brice RM, Roesler JF. 1966. The Exposure to Carbon Monoxide of Occupants of Vehicles Moving in Heavy Traffic. Journal of the Air Pollution Control Association. 16(11): 597-600.

ElKarim MAA, Khogali M, Zeqlam H. 1991. Traffic air pollution in Kuwait: preliminary results for nitrogen oxides and carbon monoxide. Science of The Total Environment. 106(1-2): 111-119.

Hasan M, Rahman S, Paul N, Halder P, Alam M, Raquib M, Islam M, Khan P. 2013. Analysis of Exhaust Emission of Vehicles in Dhaka City of Bangladesh. Global Journal of Science Frontier Research, Environment \& Earth Science 13(2): 51-55.

Holloway T, Levy H, Kasibhatla P. 2000. Global distribution of carbon monoxide. J. Geophys. Res.Atmos. 105: 12123-12147.

Khana IA, Arsalan MH. 2017. Spatial Pattern of Traffic Induced Carbon Monoxide and Potential Health Risk in Karachi. Preprints. 2017110175 (doi: 10.20944/preprints201711.0175.v1).

Levy R J. 2015. Carbon monoxide pollution and neurodevelopment: A public health concern. Neurotoxicology and teratology. 49: 31-40.

Odekanle EL, Fakinle BS, Jimodac LA, Okedered OB, Akeredolua FA, Sonibarea JA. 2017. In-vehicle and pedestrian exposure to carbon monoxide and volatile organic compounds in a mega city Urban Climate. 21: 173-182.

Rozante JR, Rozante V, Alvim DS, Manzi AO, Chiquetto JB, D'Amelio MS, Moreira DS. 2017. Variations of Carbon Monoxide Concentrations in the Megacity of São Paulo from 2000 to 2015 in Different Time Scales. Atmosphere. 8: 81.

Stephens S, Madronich S, Wu F, Olson JB, Ramos R, Retama A, Muñoz R. 2008. Weekly patterns of México City's surface concentrations of CO, NOx, PM10 and O3 during 1986-2007. Atmos. Chem. Phys. 8: 5313-5325.

Topacoglu H, Katsakoglou S, Ipekci A. 2014. Effect of exhaust emissions on carbon monoxide levels in employees working at indoor car wash facilities. Hippokratia 18(1): 37-39.

Venter ZS, Aunan K, Chowdhury S, Lelieveld J. 2020. COVID-19 lockdowns cause global air pollution declines with implications for public health risk. $M e d R_{x} i v$.

Zhao D, Chen H, Shao H, Su X. 2018. Vehicle Emission Factors for Particulate and Gaseous Pollutants in an Urban Tunnel in Xi' an, China. Journal of Chemistry. 